\title{
Selection of Standards in Naval Programmes: Harmonising Classification Rules with Commercial and Military Standards
}

\author{
G G Salas-Berrocal, MSc., SIMarEST ${ }^{\text {a, b }}$, C Marrugo-Puerta, MSc ${ }^{\text {a }}$. \\ ${ }^{a}$ The Science and Technology Corporation for the Development of the Naval, Maritime and Riverine Industries \\ (COTECMAR), Design \& Engineering Management Office, Colombia \\ ${ }^{b}$ Corresponding Author. Email: gsalas@cotecmar.com
}

\section{Synopsis}

\begin{abstract}
This paper presents the findings of an extensive literature review conducted by the authors to elucidate the main aspects to be considered in the selection of rules, standards, and regulations in Naval Projects, as the difference between military and commercial standards, the implications of the use of COTS, and the close relationship between the standards and requirements. Finally, some insights and lessons learned from the harmonisation process carried out by for the design process of the Colombian Navy warships are provided.
\end{abstract}

Keywords: Naval rules; military and commercial standards; prescriptive and goal-based regulations; Naval Classification Rules; COTS in naval projects.

\section{Introduction}

Traditionally, the concept of classification and the application of rules and standards have been mostly linked to the design and construction of commercial vessels. Indeed, naval ships are usually exempted from compliance with most of the international maritime conventions. However, National Authorities and Navies who operate military vessels have tried to adopt regulations and standards as far as possible, provided that there is not a compromise in the performance and capabilities of their ships.

In a general context, rules and standards are necessary to assure that products and services comply with the expected levels of quality, safety, reliability, efficiency, and eco-friendliness. In the case of naval ships, the application of specific standards supports the compliance of their special requirements in terms of maintainability, survivability, and interoperability. Therefore, the selection of rules, standards, and regulations in a naval programme is a process to be undertaken during its early stages due to its tight relationship with the functional requirements and cost.

Nowadays, Classification Societies have increasingly growing participation in the planning and execution stages of naval programmes. Consequently, the process of development and updating of Naval Classification Rules (NCR) has been constant, focusing on the platform and its main aspects, such as stability, structural integrity, propulsion and electric power generation, fire safety, and so forth. However, since the NCR usually exclude mission systems, tactical communications and signature management there is a 'gap' to be covered by military standards. On the other hand, the implementation of Commercial-off-the-shelf (COTS) technologies for noncritical systems opens the possibility to apply some commercial/merchant standards, which tend to be less stringent than military standards. Hence, it is necessary to harmonise the use of the NR with other types of standards in such a way that the Naval Programme aligns with a mature and consistent set of rules to support the functional requirements.

This paper is aimed to outline the main aspects involved in the selection and harmonisation of standards and regulations in naval projects.

\section{The regulatory framework in naval shipbuilding}

Naval ships are exposed to multiple hazards as a result of the roles they need to perform during peacetime and wartime. For this reason, warship design must integrate very particular features to increase their probability to survive attacks and continue in operation. Similarly to the evolution process suffered by merchant ship design, where some of the main lessons learned came from disastrous accidents, naval ship design also took advantage of 
the experience from the past and started to lay the foundation of its own 'good practices' (Barker and Campbell, 2000). Eventually, these good practices began to be documented and led to the first standards.

Nowadays, there are thousands of documents that establish a regulatory framework for naval shipbuilding: Rules, standards, and regulations. Although these terms sometimes are used indistinctively, differences can be found:

Rules are not by themselves mandatory. They are issued by Non-Governmental Organisations and their compliance may be constituted mandatory only if a National Maritime Administration make them part of the National Legislation.

- $\quad$ Regulations tend to be statutory and are issued by a National or International Maritime Administration.

- Standards gather the good practices in a specific subject and provide technical guidelines, requirements, and specifications to be followed by designers and shipbuilders. These are aimed to achieve commonality in interfaces, design criteria, manufacturing processes, test methods, and so on.

The International Maritime Organization (IMO) is the maximum international authority who sets maritime regulations for safety, security, and environmental performance. On the other hand, rules are issued by the Classification Societies. Finally, standards can be made by different organisations, which can be focused on military or commercial applications. Examples of military standards are the MIL, issued by the U.S. Department of Defence (DoD) and the STANAG (Standardization Agreement) and ANEP (Allied Naval Engineering Publication), issued by the North Atlantic Treaty Organization (NATO).

\section{Military versus commercial standards}

The rise in the development and establishment of military standards started after the end of World War II. In the case of the United States, between 1950 and 1980 the U.S. DoD produced and kept in force a considerably high number of standards with precise specifications for the fabrication and operation of military equipment (Cathcart et al., 2010, p. 461). This trend was especially notorious in the field of electronics since most of the technological advancements in this area came from military applications.

As argued by Curry et al. (2002), from the decade of 1990 the widespread growth of the demand of electronic equipment for commercial applications, favoured by the appearance of new technologies, caused that industrybased standards started to take advantage over military standards. Therefore, the equipment made under military standards became bespoke for specific applications and, in consequence, these turned out to be more expensive and difficult to maintain. Moreover, with significant budget constraints for defence, the cost of development and maintenance of the military standards available at that moment, as well as the compliance procedures to be undertaken throughout the life cycle of the vessel became unsustainable for the governments (Lorell et al., 2001). As a result, there is a widely accepted perception that warships designed, built, and maintained in compliance with naval/military standards are more expensive than those applying a mixture of commercial and naval standards (Aitken and Jones, 2007; Arena et al., 2006, p. 68; Lorell et al., 2001, p. 4). Furthermore, survivability features are often pointed out as one of the most important cost-drivers in surface combatants (Martin, 2007; Thornton et al., 2007).

\subsection{Commercial standards and warship's affordability}

Some authors have reported cost savings related to the application of a 'commercial-like' approach in naval and military acquisition programmes. For instance, Markowski et al. (2008) presented a comparison between the cost of combat systems in naval vessels, which is approximately the $15 \%$ of the overall cost of the platform for ships with affinity to commercial standards, whereas it might ascend to $50 \%$ for naval combatants with compliance to naval standards. Similarly, Post (2003) illustrated the implementation of a mix of naval and commercial standards in the Royal Netherlands Navy warship, with estimated savings of $15 \%$ in the construction of the $D e$ Zeven Provinciën (F802) class frigates. Other references can be found in the U.S. Navy LX(R) Amphibious Ship Programme, currently under development (O’Rourke, 2017; Scott and Grace, 2013).

The adoption of commercial and industry-based standards and specifications has been proved to be a recommendable option to limit the total ownership cost in naval programmes, as well as a suitable measure to facilitate the logistic support throughout the life cycle (Aitken and Jones, 2007; Ashe et al., 2009). However, several challenges appear when it comes to other relevant aspects of warship design, such as Reliability, Availability, and Maintainability (RAM), survivability, quality, and risk.

\section{Challenges in the application of commercial standards in naval acquisition programmes}

The majority of the commercial equipment are not designed for optimal operation in the challenging conditions of the marine environment and, mostly, naval warfare: 
- $\quad$ High levels of noise, vibrations, salinity, and temperature.

- Demanding requirements of survivability.

- $\quad$ The need to maintain the continuity of service.

- $\quad$ Electromagnetic emissions from diverse sources, which can cause Electromagnetic Compatibility (EMC) issues in susceptible equipment.

- $\quad$ Multiple missions and different kinds of threats (regular and irregular) in constant evolution.

Consequently, the use of commercial technology in a warship can lead to some vulnerabilities, which are more evident in some areas than others. An example of this situation can be found in the management of the Electromagnetic Compatibility (EMC) in naval vessels.

Literature outlines the fact that there are clear differences between industry-based and naval standards for electronic equipment, taking into account the EMC perspective (European Committee for Standardisation (CEN), 2005; Leersum et al., 2013; Pierce, 2009). Leersum et al. (2013) summarize the existing gap between military and Commercial-Off-The-Shelf (COTS) equipment in three aspects: Different operating environments, different testing methods, and the type and number of threats used to test military equipment, which is broader than the parameters applied for trials in commercial equipment. Besides, Pierce (2009) stresses that currently there are not a set of commercial standards covering the whole frequency range used in modern warships. Hence, due to the lack of experimental data, system integrators cannot accurately predict if a COTS equipment will operate correctly in a military environment. As a result, it is not advisable to use COTS for equipment with tactical functions (Dhingra and Nara, 2006).

\section{Finding the gap in the selection of standards: Understanding their basis}

Regarding regulatory framework, ship design needs to integrate three key aspects, as per Figure 1:

- $\quad$ Functional requirements, which define the ship and its main features;

- International Maritime Organisation (IMO) regulations, which are intended to ensure the safety of life at sea;

- $\quad$ Classification rules, which contain the specific regulations to be applied for design and construction.

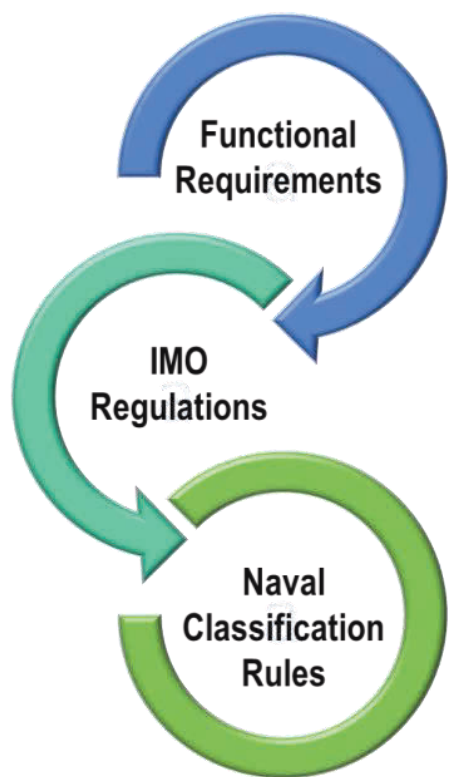

Figure 1: Elements involved in the maritime regulatory framework

As explained by Schank et al. (2014), the functional requirements must be underpinned by a proper mix of standards and regulations, which involve technical and safety standards, as well as classification rules. Consequently, the interaction between requirements and standards in a naval programme should start from its very early stages, bearing in mind that the selected standards must be 'stable, mature, and consistent before initiating any design work' (Schank et al., 2014, p. 95). This interaction is depicted in Figure 2, which shows an adaptation of the classic Systems Engineering ' $V$ Model' to represent the main processes involved in a typical naval acquisition project, where the definition of standards is presented as a parallel process to the requirements elucidation. 
In order to have a better understanding of the basis of standards in the maritime industry, the concepts of prescriptive and performance standards are visited below.

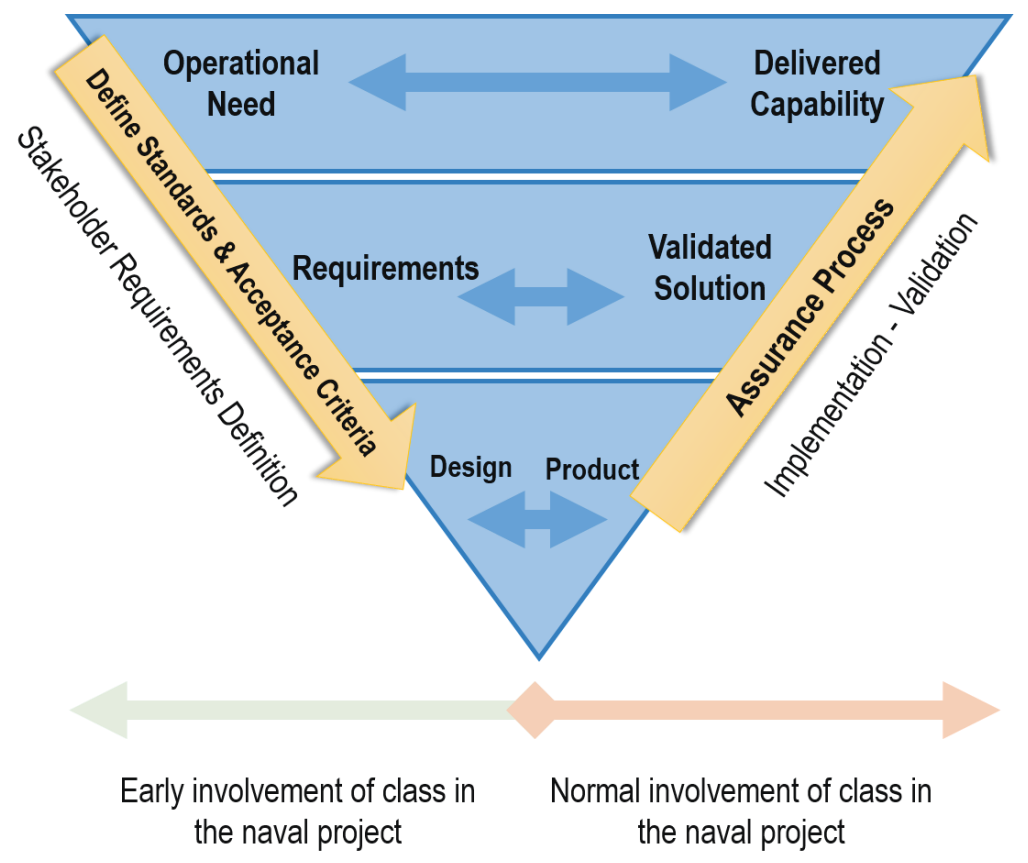

Figure 2: V Diagram of a naval acquisition project: Integration of rules, standards, and regulations

\subsection{Prescriptive standards}

The 'good practices', discussed in section 2, eventually became prescriptive standards in the maritime industry. They provide specific guidelines to be undertaken in order to receive a compliance certification. Indeed, it could be argued that prescriptive standards gather the 'know-how', built over the years by Classification Societies, Shipbuilders, Shipowners, and Operators. However, several authors have claimed that this type of standards have some limitations and drawbacks, especially when it comes to their application in new naval acquisition projects:

- They favour what Barker and Campbell (2000) called the 'compliance culture', which means that the actors of the shipbuilding process might be tempted to adopt a simplistic view, based on the mere fulfilment of the actions dictated by the standard (Hoppe, 2005; Penny et al., 2001). According to this perspective, the risk management and legal responsibility are considered to be in charge of the issuer of the standard, while in reality these aspects cannot be disconnected from the Shipbuilders and Shipowners/Operators.

- $\quad$ Prescriptive standards require a significant effort in maintenance and updating, due to the rapid changes in technology and the incorporation of innovative solutions in ship design and construction. Hence, they are not recommendable for projects with a high component of evolving technologies (Tupper, 2013).

\subsection{Performance standards: The Goal-Based approach}

On the other hand, performance standards are aligned to a 'goal-based' approach, which sets objectives to be achieved rather than a particular way to accredit the compliance. Therefore, this type of standards does not provide specific solutions, as prescriptive standards tend to do.

Nowadays, the goal-based approach has been introduced by most of the major regulatory bodies in the maritime industry due to its benefits, including flexibility in the design and implementation of novel technical solutions that satisfy the required levels of safety and reliability (Tupper, 2013), as well as a holistic approach to the requirements management. The IMO is now applying a goal-based philosophy into its regulations on safety, environmental matters, and security. A relevant example is the regulation II-1/3-10 of the International Convention for the Safety of Life at Sea (SOLAS), which is addressed to the ship construction standards for bulk carriers and oil tankers and entered into force in 2012 (International Maritime Organization, 2015). Other IMO safety standards in accordance with the goal-based approach are currently in the transition period to their implementation, such as the International Code of safety for ships using gases or other low flashpoint fuels (IGF Code). 
In parallel efforts, the NATO led the project to encompass a goal-based philosophy in a safety standard for naval ships. This was translated into the Naval Ship Code (NSC) or ANEP-77, a standard comparable to SOLAS but featuring some particular criteria related to the naval context, as missions and operational patterns. The aim of the NSC is to set a regulatory framework for safety assurance. A comprehensive view on the main aspects of the NSC is provided by Delpizzo and Valluri (2017).

\subsection{Are prescriptive and performance standards opposite? An integrating view}

At this point, two different perspectives in the underlying philosophy of standards and regulations have been presented. So, the question that arises is if prescriptive and goal-based standards are conflicting between each other and if the selection of one of these approaches in a naval programme implies avoiding the other. As asserted by Delpizzo and Valluri (2017), performance standards are intended to establish a high-level framework and, therefore, can be supported by prescriptive standards to verify the compliance of the goals. Moreover, goal-based standards can acquire a prescriptive extent if required in a particular area, while keeping a general level in other subjects. As a result, it is possible to argue that prescriptive and goal-based standards are, instead of opposite, complementary.

The way the NSC is structured provides an interesting insight into how goal-based and prescriptive standards complement each other. Figure 3 shows the hierarchy of tiers used by the NSC, where the first three tiers contain the overall aim, the goals per chapter, the functional objectives, and the performance requirements, respectively. These tiers are related to high-level statements aimed to establish safety goals, whose level of detail increase while descending through the hierarchy (NATO, 2014). On the fourth tier, the solutions are found. These are basically prescriptive standards to assure the compliance of the safety goals by means of verification throughout the life cycle of the vessel. Whereas the high-level statements present common objectives for all naval ships (such as the safety of life at sea, protection of the environment, or the health and welfare of the crew), the prescriptive level can be different for each naval vessel, since the technical solutions ought to adapt to particular aspects as the missions and roles, the technologies to be installed on board, RAM considerations, budget constraints, and so on (von Oldershausen, 2014). Figure 4 illustrates an example of the implementation of goal-based and prescriptive approaches through the hierarchical methodology in the NSC: It shows from the most general level up to the adoption of a specific regulation to achieve the compliance of the goal stated in tier 1 .
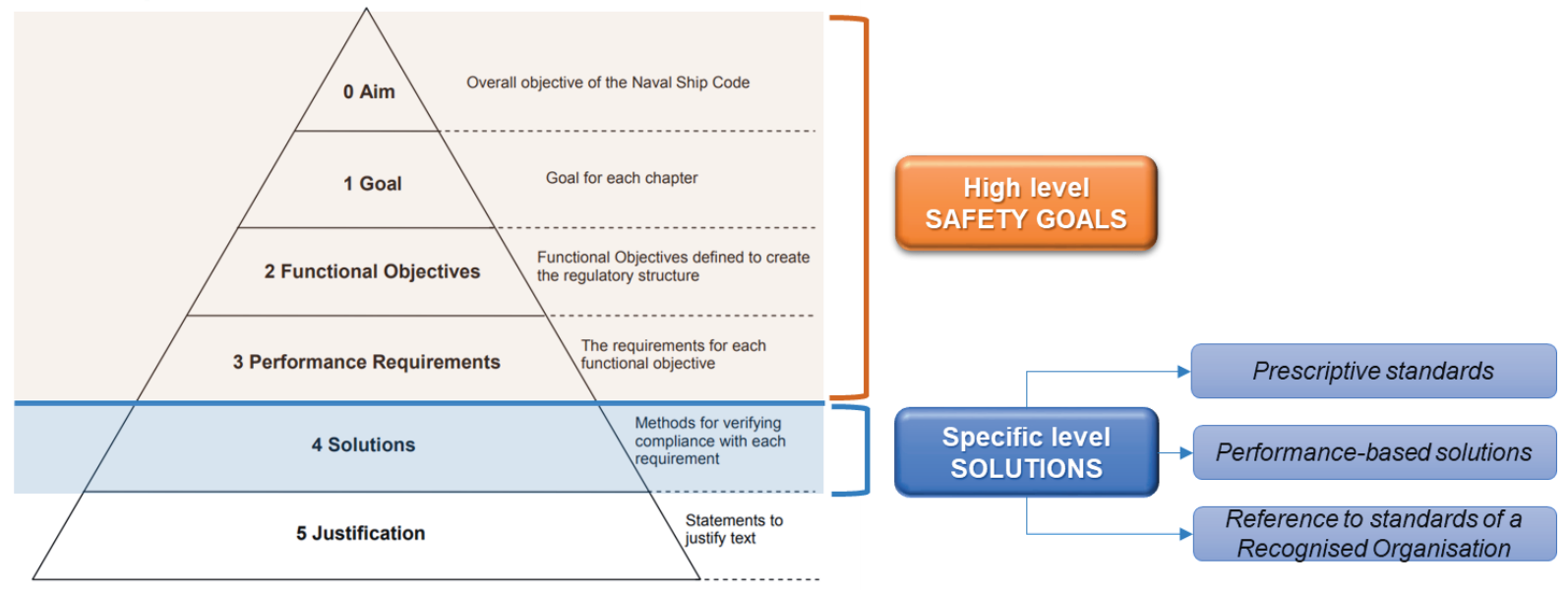

Figure 3: Structure of the NSC and the integration of goal-based and prescriptive approaches (NATO, 2014)

In summary, the essence of a goal-based standard is to be a 'standard of standards'. For this reason, an essential part of the implementation of a goal-based approach is the selection of the appropriate mix of standards, rules, and regulations to underpin the primary objectives. In the case of the NSC, there are intermediate steps to achieve the fulfilment of the top-level aims during the design, construction, and operation of a naval vessel, as follows (Figure 5):

- Selection of the Classification Society and its applicable rules. These rules can be 'tailored' to suit some specific warship requirements, as it will be discussed in 6.2 .

- National Naval Standards, which are included in the owners requirements.

- Ship's Technical Specification, condensed in a Concept of Operations Statement. 
- $\quad$ Ship's design, which uses as inputs the Concept of Operations and the Classification Rules.

One of the elements outlined by Figure 5 is the participation of the Classification Society, which will be analysed in more detail in the following sections.
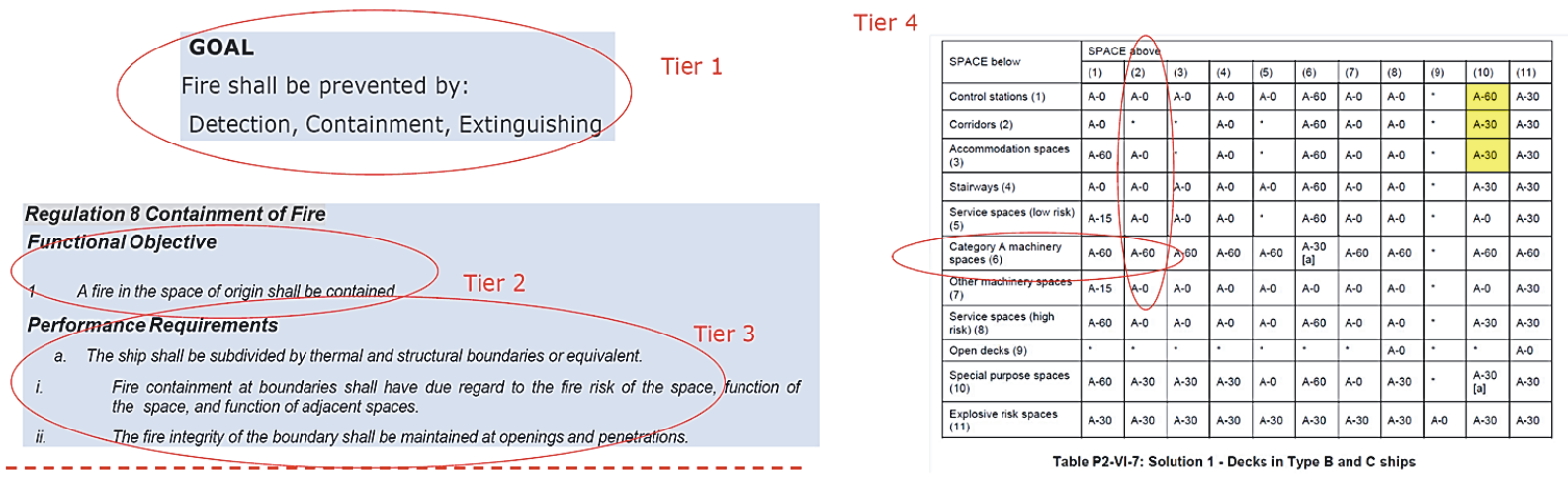

Figure 4: Example of the implementation of the tier structure in the NSC (Fire safety) (NATO, 2014)

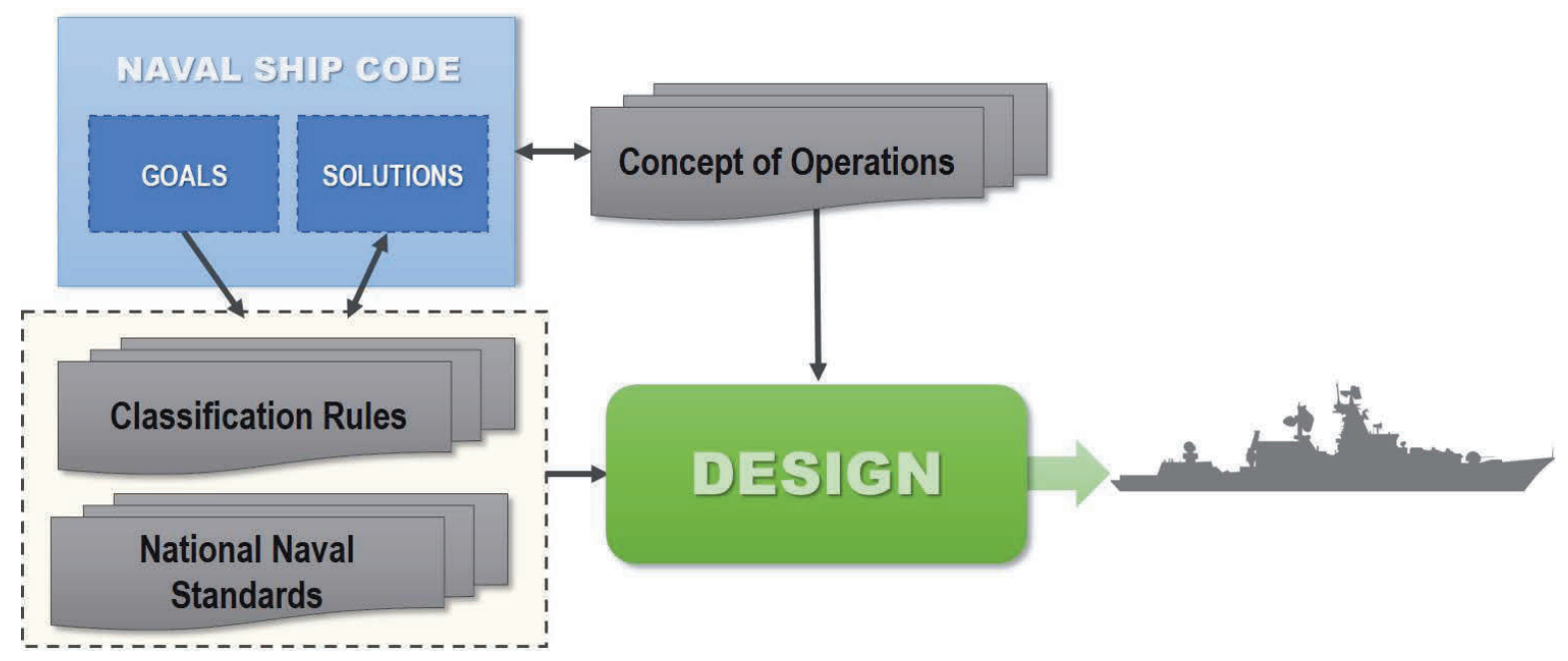

Figure 5: Relationship between the NSC, NCR and operational requirements in naval ship design

\section{Harmonising rules and standards for a sound regulatory framework in naval programmes}

From the authors' perspective as ship designers, involved in early stages of naval design for the Colombian Navy, the task of selecting a balanced set of standards, rules, and regulations to apply in a particular project can be complex and challenging, even unclear if the concepts that have been discussed previously in this paper are not yet familiar. Although there is not a unified method to find the right mix of classification rules, and military or commercial standards (of either prescriptive or goal-based philosophies), the literature presents relevant recommendations that can serve as guidance during the process of selection and harmonisation. The main findings on this topic are presented hereinafter:

\subsection{Participation of all the stakeholders}

As discussed in section 5, for the success of a naval project it is crucial to undertake the selection of standards from its very early stages. For this purpose, it is necessary to involve all the stakeholders: ship designers, shipbuilders, the Navy, the Naval Authority, and Classification Societies, through a collaborative work strategy (Lloyd's Register Marine, 2014). This cooperation must be tighter as the complexity of the project increases. In the marine/naval industry, it is usual to see that the size of design teams and management offices undertaking 'simple' projects, such as small or auxiliary naval vessels (whose roles are closer to a commercial-like approach) is reduced. Moreover, in this type of projects the initial phase (i.e. concept design) is carried out mostly from the Naval Architecture perspective. Indeed, this corresponds to practical and economic reasons; however, when it comes to a complex naval programme, such as a surface combatant with a full military operation, it is strongly 
recommended to adopt from the beginning a holistic view, by integrating specialists from different disciplines including Marine Engineering. This methodology of 'concurrent design', which is extensively used for engineering and production design stages, can be extended to the selection and harmonisation of standards.

\subsection{Analysis of the applicability of the available standards}

One of the benefits of the early involvement of specialists in different disciplines is that it is possible to analyse the applicability of the available standards for each functional area. LR recommends also evaluating in terms of compatibility and interfaces, to avoid the selection of contradictory standards (Lloyd's Register Marine, 2014).

As a result of this analysis, it might be found that some regulations can be applied only to a partial extent or that some requirements need to be reinforced with alternative standards. For this reason, the early involvement of the Classification Society in the naval programme is emphasised, so that possible gaps and overlaps between the NCR and the other applicable standards can be identified. This process is known as 'tailoring' and is conducted to determine the final set of standards to be applied, as well as the required adaptations for their implementation such as exemptions, exceptions, scopes, etc. (Ashe et al., 2007, p. 211).

\subsection{A criterion on the use of commercial standards}

Figure 6 schematises a proposed approach for the application of commercial standards in naval projects. The selection of the standard to be applied and the feasibility of using a commercial standard depends on the impact of the equipment or system in the primary capabilities of the vessel. Therefore, it is suggested to adopt military standards for those design features with a high impact in the main capability and functionality, whereas the specifications with a low impact can be asserted by commercial standards or other international/national regulations, including standards of IMO and the National Maritime Authority.

There is not a rule-of-thumb to determine which systems have the higher or lower impact in the overall performance of a warship, and this will depend on the expertise of the project team to identify the critical areas, based on the Concept of Operations and particular constraints as the cost and risk.

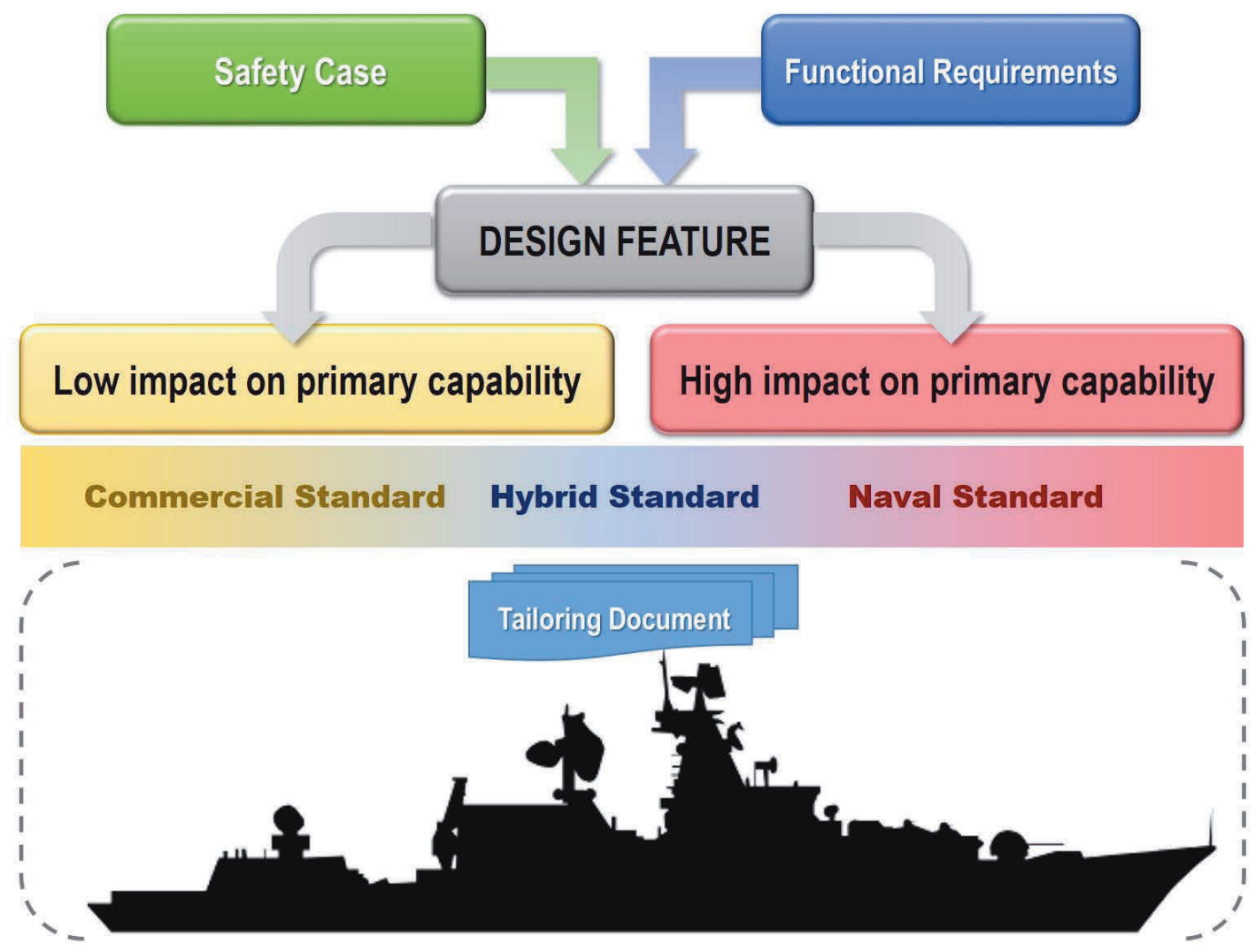

Figure 6: Selection of standards in a naval programme 


\subsection{Potential benefits of the NSC}

Although the implementation of the NSC is not mandatory and it is a relatively new concept, its goal-based approach can provide potential benefits in emerging naval programmes. Von Oldershausen (2014) states some of these benefits:

- The NSC offers a common safety regulatory framework for naval ships.

- Due to its goal-based philosophy, it allows the implementation of innovative technical solutions. This point is particularly relevant, considering that the naval vessels designed today will be in operation for the next 30 or 40 years.

- $\quad$ It can be harmonised (or tailored) with NCR and other standards.

- It allows the reduction the number of standards, replacing many national naval regulations.

\subsection{The regulatory framework must be in line with the acquisition strategy}

Nowadays, Navies appeal to diverse acquisition strategies for the procurement of their warships. Experiences from different naval programmes show that the selection of the NCR and other alternative standards to be applied is highly dependent on the acquisition strategy. When acquiring an existing ship design, which can be considered as a Military-Off-The-Shelf (MOTS) vessel, or an evolved MOTS vessel, it is very likely that the choice of the Classification Society has been already made. In this case, a change to suit a different regulatory framework will cause additional costs due to design modifications and re-classification. For new designs, there can be more freedom in the selection of a particular Classification Society (Schank et al., 2014, p. 102).

\section{A final reflection: Lessons learned from the Colombian experience}

Figure 7 illustrates the roadmap of naval projects developed for the Colombian Navy. It can be observed that gradually these have increased in complexity, starting from small riverine patrol boats to reach the level of the Offshore Patrol Vessels (OPV). The final aim of this evolution goes towards the development of the future generation of Colombian warships.

From the perspective of rules and regulations, these projects have transitioned from the safety and technical assurance of the National Maritime Authority to the adoption of the Classification approach. Nowadays, some of the guidelines presented in section 6 are already in implementation, with the purpose of achieving a sound regulatory framework for the upcoming projects. For instance, Figure 8 summarises the methodology proposed by the authors to conduct the analysis of applicability.

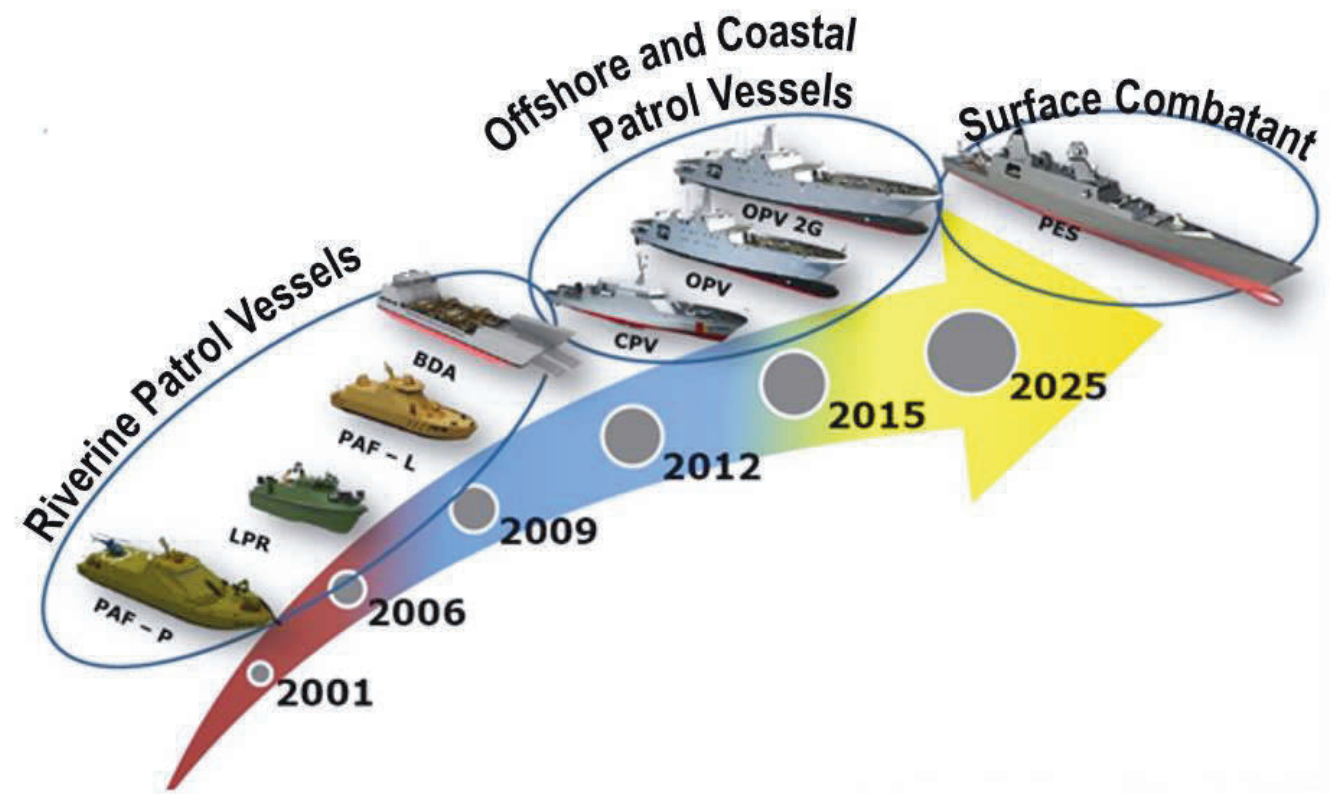

Figure 7: Roadmap of projects for the Colombian Navy 


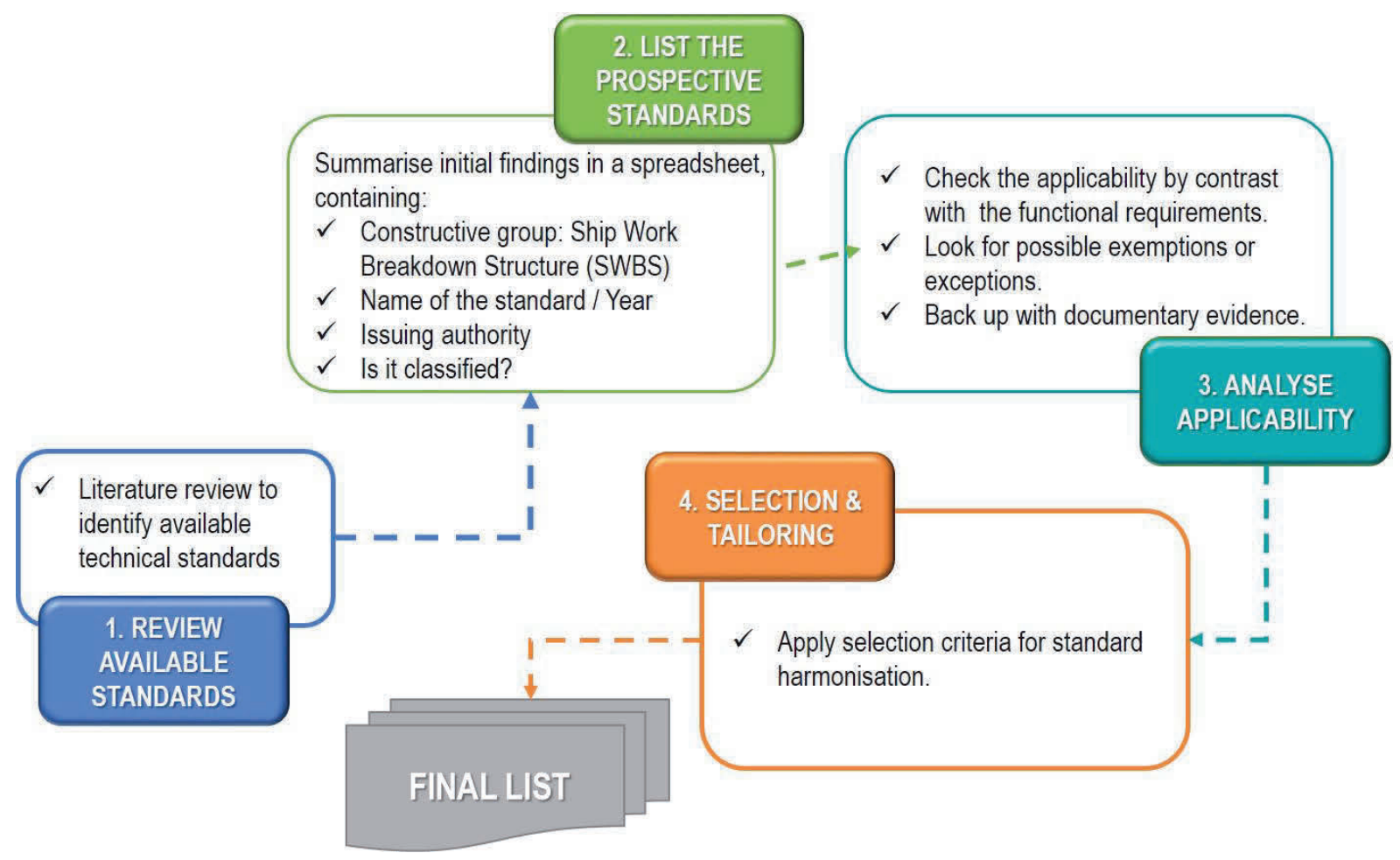

Figure 8: Methodology to conduct the applicability analysis

\section{Conclusions}

The selection of rules, standards, and regulations is a process to be integrated since the early stages of a naval programme, through a collaborative methodology where all the stakeholders are involved: designers, shipbuilders, the Navy, and the Classification Society. During this process, particular attention must be given to verify the applicability of the available standards, to identify possible conflicts or the need of exceptions of compliance. This analysis should be formalised in a Tailoring Document, which reflects the way that requirements are met through the regulations.

Some Navies have started to apply a commercial-like approach in warship design, using COTS equipment and standards as a way to improve ship's affordability. Although there is not a final word about the pros and cons of this approach, it is worthy to bear in mind that, if used, it is recommended to select systems with low impact in the main capability and functionality of the vessel.

Furthermore, considering that naval programmes developed in the actuality will produce the warships to operate during the next three or four decades, the implementation of the NSC is an option to appropriate the benefits of a goal-based regulation. Also, it allows building a sound regulatory framework with the NCR and other prescriptive standards, where required. Finally, when using prescriptive standards, it is important to keep them updated. It is suggested to monitor regularly the status of this standards.

\section{Acknowledgements}

The authors would like to thank the support given by COTECMAR and Colombian Navy for the development of this paper, particularly to the PES Project team members in both institutions. Finally, the views expressed in this paper are that of the authors and do not necessarily represent the views and opinions of COTECMAR and the Colombian Navy.

\section{References}

Aitken, A., Jones, S., 2007. What price navalisation in military support ships? Presented at the Military Support Ships, RINA, Londres, pp. 62-63.

Arena, M.V., Blickstein, I., Grammich, C.A., Younossi, O., 2006. Why Has the Cost of Navy Ships Risen?: A Macroscopic Examination of the Trends in U.S. Naval Ship Costs Over the Past Several Decades. Rand Corporation. 
Ashe, G.M., Finney, R.R., Gabel, D.G., 2007. Naval Vessel Rules: Taking Naval Ship Classification to a New Plateau. Discussion. Transactions of the Society of Naval Architects and Marine Engineers 115, $207-223$.

Barker, C.F., Campbell, C.B., 2000. Risk Management in Total System Ship Design. Naval Engineers Journal 112, 355-365. https://doi.org/10.1111/j.1559-3584.2000.tb03342.x

Cathcart, T., Fowler, K., Tyler, D., 2010. 6. Systems Engineering in Military Projects, in: Mission-Critical and Safety-Critical Systems Handbook - Design and Development for Embedded Applications. Elservier, Newnes, p. 25.

Curry, R., Ashe, G., Novak, D.S., 2002. Applicability of High Speed Craft and High Speed Naval Craft Classification Rules to Current Mission Requirements. Journal of Ship Production 18, 208-215.

Delpizzo, R.D., Valluri, S., 2017. An Introduction to NATO Standard ANEP (Allied Naval Engineering Publication) 77 and Its Application to Naval Ships. Ciencia y tecnología de buques 11, 75-88. https://doi.org/10.25043/19098642.153

Dhingra, C.P., Nara, S., 2006. Convergence and divergence between MILS and COTS standards "Commercial Off The Shelf (COTS) equipment" - An EMC perspective, in: 2006 9th International Conference on Electromagnetic Interference and Compatibility (INCEMIC 2006). Presented at the 2006 9th International Conference on Electromagnetic Interference and Compatibility (INCEMIC 2006), pp. 181-188.

European Committee for standardisation (CEN), 2005. Recommendations issued by Expert Group 7 "Electromagnetic environment" on their selection of standards (Report of the CEN WS 10 EG7 "Electromagnetic environment" No. CEN/WS10/EG7/N051). European Commitee for Standardisation.

Hoppe, H., 2005. Goal-based standards. WMU J Marit Affairs 4, 169-180. https://doi.org/10.1007/BF03195072

International Maritime Organization, 2015. International Goal-Based Ship Construction Standards for Bulk Carriers and Oil Tankers.

Leersum, B.J.A.M. van, Ven, C.C.J. van der, Bergsma, J.G., Leferink, F.B.J., 2013. Design of complex naval installations and the limitations of equipment standards, in: 2013 Asia-Pacific Symposium on Electromagnetic Compatibility (APEMC). Presented at the 2013 Asia-Pacific Symposium on Electromagnetic Compatibility (APEMC), pp. 1-4. https://doi.org/10.1109/APEMC.2013.7360645

Lloyd's Register Marine, 2014. Naval ship safety assurance - Guidance for navies and shipbuilders.

Lorell, M.A., Drezner, J.A., Lowell, J.F., 2001. Reforming Mil-Specs (Documented briefings). RAND Corporation.

Martin, A.A., 2007. Survivability and the affordable warship, in: The Affordable Warship. Presented at the RINA Warship 2007, RINA, Bath, United Kingdom.

NATO, 2014. Naval Ship Code (ANEP-77), F, ver. 1. ed. NATO Standardization Office (NSO), Brussels.

O’Rourke, R., 2017. Navy LX(R) Amphibious Ship Program: Background and Issues for Congress.

Penny, J., Eaton, A., Bishop, P.G., Bloomfield, R.E., 2001. The Practicalities of Goal-Based Safety Regulation, in: Aspects of Safety Management. Springer, London, pp. 35-48.

Pierce, J.D., 2009. Electromagnetic Compatibility (EMC) requirements for Military and Commercial Equipment (Masters Thesis). Naval Postgraduate School, Monterey, California.

Post, R., 2003. Affordability \& flexibility in Naval patrol vessels. Naval Forces; Aldershot 24, 130-131.

Schank, J.F., Arena, M.V., Kamarck, K.., Lee, G.T., Birkler, J., Murphy, R.E., Lough, R., 2014. Keeping Major Naval Ship Acquisitions on Course - Key Considerations for Managing Australia's SEA 5000 Future Frigate Program. RAND Corporation.

Scott, R., Grace, J., 2013. USN looks at commercial specs for LX(R) amphibious ship. Jane's Navy International; Coulsdon 118.

Thornton, J.S., Courts, M.D., Robb, M., 2007. Making warship survivability affordable, in: The Affordable Warship. Presented at the RINA Warship 2007, RINA, Bath, United Kingdom.

Tupper, E.C., 2013. 2. Definition and Regulation, in: Introduction to Naval Architecture. Elservier, Butterworth Heinemann, Oxford, p. 24.

von Oldershausen, C., 2014. Naval Ship Code - Challenge or benefit for the navies of the world? 